УДК 130.2

DOI: 10.18101/1994-0866-2020-1-23-31

\title{
АРХАИЗАЦИЯ СОВРЕМЕННОГО ТОПОСА РОССИИ
}

\section{(c) Жамсаев Михаил Батожапович}

кандидат философских наук, старший преподаватель, Бурятский государственный университет имени Доржи Банзарова Россия, 670000, Улан-Удэ, ул. Смолина, 24а

E-mail: mzhamsaev@bk.ru

\section{(C) Чагдурова Эржена Дондобовна}

кандидат философских наук, доцент, Бурятский государственный университет имени Доржи Банзарова Россия, 670000, г. Улан-Удэ, ул. Смолина, 24а

E-mail: chagd60@mail.ru

В статье рассматривается ситуация современного кризиса в России. Авторы, раскрывая системный характер кризиса, отмечают осуществляющуюся архаизацию топоса по всем ключевым направлениям культурного развития. Архаизация является маркером деградации, упрощения культурной системы, находящейся в глубоком структурном кризисе, охватывает не только социально-экономическую сферу, но и сознание современных россиян, прибегающих к возрождению родоплеменных отношений и ценностям языческой культуры. Особую опасность авторы видят в растущей криминализации всех сфер жизни в стране, в диалектическом взаимодействии власти, бизнеса, правоохранительных органов, осознание чего еще более угнетает рядовых граждан. Выход из сложившейся ситуации авторы видят в необходимости должного понимания властью роли образования и науки, без чего невозможны подъем экономики страны, решение социальных проблем и усложнение топоса.

Ключевые слова: архаизация; топос; картина мира; Россия; кризис; переходный период; криминальная среда; образование; экономика; субкультура.

\section{Для цитирования}

Жамсаев М. Б., Чагдурова Э. Д. Архаизация современного топоса России // Вестник Бурятского государственного университета. Философия. 2020. Вып. 1. С. 23-31.

Период культурного развития, охватывающий последние три десятилетия, характеризуется затянувшимся кризисом, который не движется к своему завершению, а входит в новую фазу. Объясняется это некорректным выбором стратегии социально-экономических преобразований, в которой вместо ускоренной модернизации средств производства стимулировалось формирование неких внешних характеристик: «наличия основных элементов рыночной экономики, рыночных институтов, рыночного поведения субъектов» [1, с. 46]. При этом «сложившиеся в России рыночные отношения и механизмы во многом являются еще неразвитыми и деформированными... усилилось отставание от развитых 
стран по многим содержательным показателям; экономический рост в России в 2000-е гг. не был качественным и устойчивым, не сопровождался глубокими технологическими и структурными сдвигами, а две за последние 8 лет кризисные полосы обнажили хрупкость и уязвимость национальной экономики» $[1$, с. 47].

Глубина кризиса, в котором находится сейчас Россия, внушает опасения за ее судьбу, за само ее существование в виде суверенного государства. Экономика нашей страны сегодня ориентирована на сырьевой профиль, а не на развитие национальной промышленности, разрушенной в постперестроечный период и не восстанавливающейся. Если к 1990 г. в РСФСР было 30600 дееспособных крупных и средних промышленных предприятий, то сегодня в РФ едва набирается 5 тыс. крупных и средних промышленных предприятий, в том числе и бывших советских [2], на новый технологический уровень страна выйти не в состоянии.

Другая сторона кризиса связана с тем, что система ценностей потребительства, индивидуализма и гедонизма, целенаправленно насаждавшаяся на протяжении всего постсоветского времени, дала свои плоды, и мы получили серьезные изменения в развитии личности. «Современный россиянин не способен к жертвенной борьбе за свои права он духовно и нравственно слаб, растерял те качества, которые когда-то давали ему силу для преобразований» [3, с. 125]. На смену советскому человеку пришло молодое поколение индивидуалистов, ксенофобов, космополитов и гедонистов, которые в поисках комфортной жизни стремятся любым способом покинуть Родину. Ценности общества потребления оказались не способны стимулировать население к активному поиску выхода страны из кризиса, они, напротив, еще больше углубляют кризисные настроения, ввергают в хаос массовое сознание. В ситуациях подобных изменений общество либо прилагает серьезные усилия к поиску ответа на вызов обстоятельств, либо возвращается к тем идеям, которые когда-то оказались успешными при прежних кризисах. Мы, к сожалению, наблюдаем сегодня движение по второму сценарию.

В этих условиях хочется найти причины происходящего выбора, какие-то пути выхода из сложившейся ситуации. На наш взгляд, одной из главных причин системного кризиса является архаизация современного топоса страны, с чем нам предстоит либо бороться, либо как-то суметь использовать. Представляется необходимым обосновать использование именно данной терминологии в рамках нашей работы.

Понятие «топос» пришло в культурологию из литературоведения, а в него - из риторики. Впервые Аристотелем было дано определение топоса как элемента диалектического силлогизма, исходящего не из научно обоснованных, достоверных посылок, а из вероятных, допускаемых собеседниками [4, с. 349-532]. В значении некоего отвлеченного рассуждения, с которым все согласны, от которого можно оттолкнуться и развивать свою мысль дальше, в риторике данное понятие используется до сих пор. В современном литературоведении под топосом понимают «значимое для художественного текста (или группы художественных текстов - направления, эпохи, национальной литературы в целом) "место разворачивания смыслов", которое может коррелировать с каким-либо 
фрагментом (или фрагментами) реального пространства» [5, с. 89]. При этом топосом называют, как правило, открытые пространственные образы, осмысливаемые как национальный символ. Именно такое понимание топоса стимулирует использование данного понятия как культурологической категории, близкой по содержанию «образу культуры» или «картине мира».

В то же время образ культуры и культурная картина мира - понятия, раскрывающие смысл самой культуры, представляющей собой сложную систему, состоящую из множества элементов, каждый из которых выполняет свои строго определенные функции. Культурная картина мира или образ мира - это целостное представление о мире, формирующееся в рамках определенного мировоззрения. Рядом с подобным осмыслением культуры понятие топоса выполняет скорее описательную задачу, опираясь на повседневную логику и здравый смысл. При разговоре о топосе мы можем базироваться на неких общепринятых положениях, которые никто не возьмется оспаривать или требовать для них научно обоснованной базы. Архаика является тем пространством, с которым комфортно использовать понятие топоса для раскрытия нашей проблемы.

Архаизация - процесс упрощения культурной системы, деградации ее до примитивного состояния. Этот процесс запускается в кризисных состояниях общества, находящегося в точке бифуркации, и достигает разных степеней глубины в зависимости от глубины самого кризиса, хаоса неравновесности. А. С. Ахиезер, создатель социокультурной теории России, понимает архаизацию как результат «следования субъекта культурным программам, исторически сложившимся в тех пластах культуры, которые сформировались в более простых условиях, в условиях догосударственной жизни, уже не отвечающих возросшей сложности мира, характеру и масштабам проблем» [7, с. 89]. Люди, изначально готовые к воспроизведению архаических стратегий поведения, способные оказаться во власти архетипов коллективного бессознательного, рождаются, по мнению А. А. Пелипенко, «во все времена и в любом обществе» [8, с. 316]. В ситуации кризисов, реформ, войн происходит массовое воспроизводство архаических стратегий, включающих в себя обращение к религиозным, магическим, языческим ритуалам, обрядам с целью привлечения в жизнь простого человека, обладающего соответствующим сознанием благополучия, успеха, мира и пр. Архаическое сознание вновь синкретично и, как в доисторические времена, надеется на помощь свыше, коллектива, государства, власти.

В культуре всегда одновременно присутствуют разные суверенные культурные опыты, именуемые субкультурами, и официальная, доминирующая культура. Архаические стратегии сплавляются с теми субкультурами, которые оказываются наиболее к ним восприимчивыми. В ситуации современной России мы наблюдаем архаизацию этнических культур, сохранивших в большей степени свою традиционную структуру. Именно здесь идет рост неоязычества, культа предков, проявляющийся в возрождении, актуализации и активизации родоплеменных и реципрокных отношений, поиске родословных, организации землячеств, взаимопомощи по общинному типу. Мы наблюдаем сегодня небывалый возврат в лоно 
традиционных церквей отпавших в свое время от веры атеистов, которые не прониклись религиозным служением, не пришли к внутреннему осознанию и принятию требований своей религии, но истово исполняют ритуалы, участвуют в службах, соблюдают внешние требования, маркирующие их как членов религиозного сообщества. В то же самое время они не считают для себя зазорным «на всякий случай» посетить и храмы других конфессий, обратиться за помощью к шаману, экстрасенсу. Религиозные практики, магические и мистические ритуалы вновь выполняют функцию социальной интеграции, сплочения на почве выполнения единообразных действий.

Средства массовой информации, видя интерес общества к оккультной тематике, реагируют распространением и рекламой таких передач на телевидении, как «Битва экстрасенсов» на ТНТ, «Гадалка», «Слепая», «Старец» на ТВ-3, «Невероятные истории», «Мистические истории» на РенТВ, телеканал «Спас», онлайн-каналы «Будда», «Алиф»; печатных СМИ: «Ступени Оракула», «Практическая магия», «Тайны судьбы», «Защитная магия», «Мистические истории» и т. д., не говоря уже об огромных просторах Интернета, где можно найти любую информацию по одному щелчку клавиши.

Архаизация современного топоса прослеживается в возрождении языческих, пантеистических смыслов в отношениях человека и природы, что происходит в конце прошлого века под влиянием экологического кризиса и популяризацией энвайроментализма. В 1970 г. была выдвинута гипотеза Геи, согласно которой земля - живой суперорганизм, следом появилась международная организация Гринпис, деятельность которой посвящена защите природы. В мире развивается движение за здоровый образ жизни, правильное питание, раздельный сбор мусора, то есть формируется новое экологическое сознание ${ }^{1}$ [9]. В то же время мы наблюдаем некоторый перекос в культ тела, молодости, здоровья и силы вспомним знаменитую фразу телеведущей программы «Здоровье» на «Первом канале» Е. Малышевой: «В наш век иметь морщины на лице стыдно». Стыдно болеть, стареть, дряхлеть, пропагандируется активный образ жизни пенсионерам, молодость продлила свои возрастные рамки до 45 лет, а старость начинается лишь с 75, что дает возможность осуществлять пенсионные реформы.

Преступное упрощение происходит в системе современного образования в России, которое в погоне за соответствием «международным стандартам» деградирует по все новым ФГОСам. Учитель унижен до уровня «обслуживающего персонала», школа и вуз предлагают «услуги», что влечет за собой соответствующее отношение к процессу обучения со стороны детей, родителей и общества. Вместо формирования в учащихся способности к самостоятельному мышлению, целостного мировоззрения, осознания своего места в жизни система среднего образования озадачена доведением до автоматизма способности к решению раз-

\footnotetext{
${ }^{1}$ Пантеизм - что это такое, история возникновения, основные направления и идеи. URL: https://womanadvice.ru/panteizm-chto-eto-takoe-istoriya-vozniknoveniya-osnovnyenapravleniya-i-idei (дата обращения: 17.01.2020).
} 
нообразных тестов. Среднее и высшее образование погружено в рутину заполнения потока документации для огромного количества надзорных органов, что не дает учителям школ и преподавателям вузов полноценно и творчески заниматься своими прямыми обязанностями: учить и воспитывать молодежь.

В современном научном познании также наблюдается «кризис научной методологии, отклонение от норм научной рациональности, размывание критериев научной истины». Эзотерическое знание активно вторгается в научное, и наука, которая раньше четко могла отграничить себя от вненаучных форм знания, теперь этого сделать не может, так как сама внутренне оказалась деконструирована [10, с. 23]. Примером может служить необычайная популярность знаменитой книги Ф. Капра «Дао физики» 1970 г., которая была переведена на многие языки и до сегодняшнего дня активно обсуждается, поддерживается и критикуется на уровне физики, философии, теософии и эзотерики. В 1999 г. защитил докторскую диссертацию по теме «Структурированное состояние воды как основа управления поведением и безопасностью живых систем» С. В. Зенин, в которой подтвердил открытие японского экстрасенса М. Эмото о том, что вода является носителем информации. Эта тема также вызывает активный интерес, авторы обвиняются в лженаучности, но есть и множество их последователей. В философии мы можем наблюдать большой интерес к работе ежегодных семинаров о современном трансцендентальном повороте в философии [11].

Однако самым аутентичным для архаизации в современной России оказался топос преступного мира, который превратился в центр его репродукции и распространения. «Это не что иное как неизжитый реликт догосударственного существования человека. Преступный мир самоорганизуется в архаические жесткие структуры - банды, преступные группы, "семьи", кланы. Зрелая преступная группа имеет достаточно сложную структуру, включающую лидера, сублидера, трикстера (провокатора), основную массу - "бойцов" и "периферию", или внешний пояс. Такая система порождает целостное пространство социального бытия. Иными словами, это древнее, чрезвычайно устойчивое социокультурное целое.

Преступный мир рождает свой этос, в котором легко узнать этос воинаварвара... Высшая моральная доблесть состоит в верности воровскому закону, в презрении к карам и "ментам" - противостоящим вору агентам государства. В идеальных образах "вора в законе" мы легко узнаем Свенельдов и Святославов, Сфенкелов и Икмаров... Культура тюрьмы создала чисто первобытное табу — "западло". Это архаическое табу качественно отлично от моральных или правовых запретов в культуре большого общества. В определенных случаях нарушение этого табу, в том числе и случайное, автоматически ведет к утрате нарушителем своего статуса и переходу его в касту париев» [12]. Зона в России - это то пространство, где доминируют нормы, обычаи, ценности первобытного общества, и, как говорит Яковенко, оно пропускает через себя пугающе большой процент граждан. Не зря на Руси популярна поговорка «от тюрьмы и от сумы не зарекайся». 
В этом огромном плавильном котле - тюрьма, зона, криминальная среда, молодежное движение АУЕ (Арестантский уклад един) - плавятся судьбы, сознание, мировоззрение миллионов, если не всего нашего общества. Язык жаргона сегодня уже не только язык улицы, подворотни, маргинального сообщества. На этом языке общаются наши дети, назначая друг другу «стрелки», называя друг друга «лохами» и т. д. Слова «понятия», «западло» используются не только для оценки соблюдения или нарушения законов воровской жизни, в повседневной речи молодежи они стали маркерами чести, достоинства, порядочности, верности, искренности, стыда и совести. В местах лишения свободы сегодня оказывается молодежь, не обучавшаяся даже в начальной школе, и здесь она имеет возможность получить образование, причем не только официальное в тюремных школах, но и у своих старших товарищей по сроку. У них молодежь получает знание классической литературы, переведенной на язык, понятный и доступный для нее. Примеры таких переводов поражают: «Но есть еще, козлы, правилка воровская. За все, как с гадов, спросят с вас» [13].

В местах лишения свободы сформировались не только свои законы, правила поведения, язык, искусство, но и социальная структура, иерархия которой выстроена по принципу первобытного сообщества со своими обрядами инициации, логикой карьерного роста, слиянием статуса с материальным благополучием, возможностью распоряжаться средствами «общака». «Общак» - своеобразный фонд помощи в преступной среде, формируется как внутри мест лишения свободы, так и вне их. Если в 90-е общак «на свободе» собирался за счет рэкета, взносов самих преступников, то сегодня АУЕ втянул в сбор общака через среднюю школу практически все население страны. Сегодня мы уверенно можем говорить о существовании преступного бизнеса, финансируемого на эти средства и приносящего огромный доход - это ряд отраслей добывающей промышленности, например полезные ископаемые, лес.

Люди, прошедшие школу жизни в «тюремных университетах», сделали карьеру на средства сообщества, продвинулись во властные структуры и оттуда «крышуют» теневую экономику, тянут вверх представителей своего сообщества, создают правящие преступные кланы, призывают с трибуны Государственной думы решать проблемы «по понятиям» [14]. Архаический топос внедрился в армию, и здесь вместо устава также господствует жизнь по «понятиям», о чем свидетельствуют происходящие здесь многочисленные трагедии. Власть, бизнес, правоохранительные органы находятся в нашей стране в диалектическом взаимодействии с криминальным миром.

Именно в архаическом топосе преступного сообщества мы видим корни растущей коррупционности нашей власти, ее беспомощности в решении проблем национальной экономики, социальной сферы, образования. Скорее всего, перестройка была вызвана к жизни тем критическим перевесом авторитета и силы криминалитета, который вырос в лагерях, тюрьмах и зонах советского времени и вступил в деловые взаимоотношения с различными властными структурами еще 
в СССР. «Формирование мафии началось задолго до перестройки, которая лишь эксплицировала его и вывела на новые горизонты» [12, с. 92].

На наш взгляд, архаизация неспособна решать основные проблемы, встающие перед современной Россией. Упрощение в ситуации всеобщего усложнения грозит энтропией, а выгодоприобретателями архаизации являются кто угодно, только не мы с вами. Значит нашей первоочередной задачей является борьба с упрощением всех структурных компонентов культуры. В стране мало сил, способных бороться с архаизацией, но, на наш взгляд, вовсе не со всеми ее проявлениями на самом деле нужно бороться. Никому не мешает возрождение традиционных культур, восстановление реципрокных отношений внутри рода. Напротив, это можно использовать для усложнения этнической карты страны, повышения национального самосознания, если выстроить цепочку: сначала я - представитель своего рода, этноса, затем - гражданин России. Пантеизация экологического сознания может быть даже усилена через актуализацию языческого отношения к природе ради решения массы экологических проблем. Художественное творчество подпитывается архаической тематикой всю историю своего существования, и актуализация интереса к остававшейся в советское время невостребованной нише оживляет современное искусство.

Совсем другое дело - экономика страны. Восстанавливать ее люди, обладающие архаическим сознанием, не в состоянии. Им необходимо обладать сложнейшими современными научными знаниями, технологическими умениями и навыками эвристического поиска, способностью принимать ответственные самостоятельные решения. Только сложные производства, новейшие технологии способны вывести Россию из плена экономического, социального и личностного кризиса, из архаического топоса в современный мир. Для этого необходимо, чтобы школа могла формировать думающую, инициативную, ответственную личность работника, востребованного усложняющейся экономикой. Система современного образования в стране способна будет справиться с возложенной на нее задачей повышения качества подготовки выпускников только тогда, когда вновь станет престижной работа учителя, на педагогические специальности вырастет конкурс, в школах будет проходить жесткий отбор кандидатов, профессиональное и карьерное развитие учителей школ и преподавателей вузов не будет зависеть от тщательного сбора портфолио, огромного количества отчетов и прочей бюрократической документации, а будет стимулироваться повышением квалификации, обменом опытом. Государство должно обратить внимание на достойную оплату труда работников образования, повышения престижа учителя, преподавателя, ученого.

Решением этим вопросов и должна заниматься та часть интеллигенции, которая способна бороться за будущее страны. Выход из ситуации архаизации один - осознание властью роли образования и науки, без чего невозможны подъем экономики страны, решение социальных проблем и усложнение топоса. 


\section{Литература}

1. Кульков В. М. Завершился ли переходный период в экономике России? // Экономические и социальные перемены: факты, тенденции, прогноз. 2015. № 4(40). ISSN 19980698. C. 45-59. URL: https://cyberleninka.ru/article/n/zavershilsya-li-perehodnyy-period-vekonomike-rossii/viewer (дата обращения: 16.01.2020).

2. 25 лет приватизации в России: что осталось от страны заводов и фабрик // Аргументы и факты. 2017. № 23. 07/06. ISSN 0204-0476. URL: https:/aif.ru/gazeta/number/35007 (дата обращения: 16.01.2020).

3. Чагдурова Э. Д., Рандалова О. Ю. Роль социальных факторов в трансформации личности // Вестник Бурятского государственного университета. 2018. № 3, т. 4. C. 117-127. ISSN 1994-0866.

4. Аристотель. Топика // Аристотель. Соч.: в 4 т. М.: Мысль, 1978. Т. 2. 687 с. (Философское наследие). URL: http://filosof.historic.ru/books/item/f00/ s00/z0000358/st000.shtml (дата обращения: 16.01.2020).

5. Прокофьева В. Ю. Категория «пространство» в художественном преломлении: локусы и топосы // Вестник Оренбургского государственного университета. 2005. № 11. ISSN 1814-6465. С. 87-94.

7. Ахиезер А. С. Архаизация в российском обществе как методологическая проблема // Общественные науки и современность. 2001. № 2. С. 89-100. ISSN 0869-0499. URL: http://ecsocman.hse.ru/data/407/860/1231/009aHIEZER.pdf (дата обращения: 16.01.2020).

8. Пелипенко А. А., Яковенко И. Г. Культура как система. М.: Языки русской культуры, 1998. 376 с. ISBN 5-7859-0047-6.

9. Шарден П. Т. де. Гимн вселенной // Феномен человека: сб. очерков и эссе. М.: ACT, 2002. 560 с. ISBN 5-17-009886-3; ФедоренкоГ. Г. Интегральный подход Ауробиндо Гхоша как попытка синтеза Западного материализма и Восточного спиритуализма // $\mathrm{Pa}-$ бочие тетради по компаративистике / Гуманитарные науки, философия и компаративистика. СПб.: Web-кафедра философской антропологии, 2003. С. 72-76.

10. Щеглова Л. В., Борисова Ю. В. Роль эзотерики в современном научном познании // Вестник Волгоградского государственного университета. Сер. 7. Философия. 2015. № 1(27). С. 22-27. ISSN 1998-9946.

11. Зенин С. В. Структурированное состояние воды как основа управления поведением и безопасностью живых систем: дис. ... д-ра биол. наук: 05.26.02 М., 1999. 207 с. РГБ ОД, 71:00-3/154-4. URL: http://www.dslib.net/bezopasnost-chp/strukturirovannoesostojanie-vody-kak-osnova-upravlenija-povedeniem-i-bezopasnostju.html (дата обращения: 13.01.2020); Капра Фритьоф. Дао физики. СПб.: ОРИС, ЯНА-ПРИНТ, 1994. 304 с. ISBN: 5-91250-571-5, 978-5-91250-571-3.

12. Яковенко И. Г. Цивилизация и варварство в истории России // Общественные науки и современность. М.: Наука, 1996. № 4. С. 87-97. ISSN 0869-0499

13. Фима Жиганец. Жужжать иль не жужжать - вот, тля, в чём заморочка // Стихи.py: сайт. URL: https://www.stihi.ru/2009/01/29/5618 (дата обращения: 17.01.2020).

14. Платова Г. Не по закону, а по понятиям // Советская Россия. 2015. 31 янв. URL: http://www.sovross.ru/articles/1180/20447 (дата обращения: 17.01.2020). 


\section{ARCHAIZATION OF MODERN TOPOS OF RUSSIA}

\section{Mikhail B. Zhamsaev}

Cand. Sci. (Philos.), Senior Lecturer,

Dorzhi Banzarov Buryat State University

24a Smolina St., Ulan-Ude 670000, Russia

E-mail: mzhamsaev@bk.ru

\section{Erzhena D. Chagdurova}

Cand. Sci. (Philos.), A/Prof.,

Dorzhi Banzarov Buryat State University

24a Smolina St., Ulan-Ude 670000, Russia

E-mail: chagd60@mail.ru

The article discusses the current crisis in Russia. Revealing the systemic nature of the crisis, we note the ongoing archaization of topos in all key areas of cultural development. Archaization is a marker of degradation, simplification of the cultural system, which is in a deep structural crisis; it concerns not only the socio-economic sphere, but also the consciousness of modern Russians applying for the revival of tribal relations and the values of pagan culture. We see a particular danger in the growing criminalization of all spheres of life in the country, in the dialectical interaction of government, business, law enforcement agencies, what even more oppresses ordinary citizens. In our opinion a way out of the current situation is in the proper understanding of the role of education and science by the authorities, without which the rise of the country's economy, the solution of social problems and the amplification of topos are impossible.

Keywords: archaization; topos; world view; Russia; crisis; transition period; criminal environment; education; economy; subculture. 